\title{
Community Participation in Environmental Conservation and Protection: A Case study of Kida community, Hawul local Government Area of Borno State, Nigeria
}

\author{
Wulha Stephen Bassi ${ }^{1}$, Abubakar Kawu Monguno ${ }^{1}$ \\ and Joseph Stephen Bassi ${ }^{2}$ \\ ${ }^{1}$ Department of Geography, Faculty of Social Sciences, University of Maiduguri, Borno State, \\ Nigeria. \\ ${ }^{2}$ Department of Computer Engineering, Faculty of Engineering, University of Maiduguri,
} Borno State, Nigeria.

\section{Authors' contributions}

This work was carried out in collaboration between all authors. Author WSB designed the study. Authors WSB and JSB performed the statistical analysis, wrote the protocol and wrote the first draft of the manuscript and managed literature searches. Authors AKM and JSB managed the analyses of the study and literature searches. All authors read and approved the final manuscript.

Article Information

DOI: $10.9734 /$ AJEE/2017/33070

Editor(s):

(1) Anthony R. Lupo, Department of Soil, Environmental and Atmospheric Science, University of Missouri, Columbia, USA. Reviewers:

(1) Saima Fazal, South China University of Technology, China. (2) John Onwuteaka, Rivers State University of Science and Technology, Port Harcourt, Nigeria. (3) David Le Poire, DePaul University, USA. Complete Peer review History: http://www.sciencedomain.org/review-history/19139

Received: $29^{\text {th }}$ March 2017

Accepted: $16^{\text {th }}$ May 2017

Original Research Article

Published: $20^{\text {th }}$ May 2017

\section{ABSTRACT}

Environmental natural resource conservation and protection (ENRCP) has been extensively promoted in recent years as an approach for pursuing nature conservation and socioeconomic objectives. The rationale for ENRCP is often compelling and convincing. This article assesses the environmental problems, level of community participation and involvement of government in ENRCP and examine the problems associated with community participation in ENRCP. The study

*Joseph Stephen Bassi: E-mail: sjbassi74@gmail.com; 
is based on our case study in Kida community, Hawul local government of Borno state, Nigeria. To achieve our objective both quantitative and qualitative data - participant observation, focus group discussions and in-depth interviews for the paper were drawn from a larger mixed methods. The results of this analysis indicates that, despite sincere willingness of communities, serious deficiencies are widely evident. It is evident that problems associated with ENRCP includes indiscriminate tree felling, bush burning, overgrazing and ignorance among community members. It was recommended that government should actively participate by providing seedlings and also educate the local community on the essence and relevance of ENRCP.

Keywords: Community; natural resources; conservation; protection; environment.

2010 Mathematics Subject Classification: 53C25, 83C05, 57N16.

\section{INTRODUCTION}

Environmental protection and conservation is an increasingly pressing issue. The speed with which the environment is destroyed far outstrips efforts to clean it up. Virtually all major conservation problems facing protected areas today have a human component [1]. In Africa, the most common of these relates to the increasing human settlement of adjacent lands and the unauthorized harvesting of resources within the protected areas [2]. Nigeria as a nation is blessed with several natural resources but is still faced with artificial man-made disasters that require protection. Largely, this destruction is as a result of the need to meet rapidly growing demands for food, water, timber, fiber, and fuel (natural resources) by man livelihoods $[3,4]$. Consequently, the livelihoods of man is dependent on natural resources [5]. Reference [6], presented that initial motivation for the world environmental protection movement came from the public, without their participation it would not exist. Furthermore, [7] presented that for conservation to be effective and successful public engagement is paramount. In the same context $[8,9]$ reported that most communities are not empowered through awareness in the sustainable use of natural resources and in some cases he presented that awareness and knowledge of natural resource conservation and management was raised but behaviour did not change.

The concept of conservation and protection was enacted as a constitutive part of both national and international law in the seventies and eighties [3]. According to [10] stated that the meaning of participation ranges from almost complete outside control, with involvement of local people, to a form of collective action in which local people set and implement their own agenda in the absence of outside initiators and facilitators. Positive attitudes of communities towards the conservation of protected areas are potentially important component of conservation, especially in the developing world where human pressure on natural resources is often high [11]. Community involvement in protecting the environment of their impacted community and related environmental issues is generally supported for its potential to provide low-cost sources of information to government agencies, increased acceptance and confidence in government decisions, empowered community members on issues that affect them and advancement of democratic ideals. Moreover, community involvement in protection and conservation of the environment by local residents can result in the collective transition from victims to agents of change [12].

Some of the major factors forcing people to environmental destruction include poverty [13], inappropriate development strategies $[3,14]$ and environmental degradation [15]. Natural resources conservation measures can only be effectively implemented if the key stakeholders are empowered to participate in the policy or legislations processes involved. It is against this backdrop that this paper seeks to assess community participation in environmental protection and conservation in the study area with emphasis on community that is active participants. 


\subsection{Objectives of the Study}

In a bid to achieve the main aim of this study the objectives include:

(i) Identify the environmental problems associated to study area;

(ii) Assess the level of community participation in ENRCP;

(iii) Government involvement in ENRCP;

(iv) Examine the problems associated with ENRCP in the study area.

\section{STUDY AREA}

The study covers one settlement purposively drawn from Hawul LGA, Borno State. The study area is located between latitude $10^{\circ} 15^{\prime} \mathrm{N}$ and $11^{\circ} 40^{\prime} \mathrm{N}$ and longitudes $12^{\circ} 00^{\prime} \mathrm{E}$ and $12^{\circ} 37^{\prime} \mathrm{E}$. It is bounded to the north by Biu local government area, Askira Uba local government are to the East, Gombi (Adamawa State) to the south, in the west by Shani and Kwaya kusar local government area. Administratively, Hawul local government area has seven administrative districts viz: Kwajaffa, Sakwa, Kwaya-Bura, Shaffa, Pama, Kidang and Mbulatawiwi.

The study area is dominated by basement complex rocks formed from previous volcanic eruptions. These have influenced the information on the topographical features such as the Marama and Vinadam inselbergs, which has an average height between $750-800 \mathrm{~mm}$. The landscapes, exhibits a predominance of volcanic cones, volcanic plugs and residual mountains. The lake Tilla is pear-shaped and is filled with water but dried up in 1975. Hawul local government area is drained by river Hawul, which has a seasonal flow and its tributary is river Kumara. It has sources between Miringa District (Biu local government area) and Gujba local government area (Yobe state). Several streams flow into the Hawul including Pidim and Tabaku among others in the southern part of the study area [16].

The area falls in tropical continental climate also known as Sudan climate. It has two distinct seasons wet and dry: the wet season is short and usually last for 5-6 months (MayOctober).
The mean annual rainfall of the area is between $650-1000 \mathrm{~mm}$ with the highest recorded in July and August. The dry season lasts for 7-8 months (October-April). The average mean temperature is about $27^{\circ}$ with temperature as low as $7^{\circ}$ and as high as $44^{\circ}$ [16]. The soil of Hawul local government area consist of wide spread series of sand, clay, silt and sandy clay soil. The area has transitional vegetation type of Northern Guinea Savanna located in the Northern Sudan Savanna area of Nigeria. It is typical parkland savanna with the landscape covered by weaving grass in the raining season and studded with solitary trees such as Butyrospermum paraduxum,(shea butter),Adonsonia digitata (Baobab), and Tamrindus indica. Trees grow very long taproots, develop thick barks and shed leaves to conserve moisture and also limit the rate of evaporation in dry season [16].

The total population of Hawul local government area was 120,733 , with 59,611 male and 61,122 female [17]. The local government is predominantly inhabited by Burah people. Others include the Hausa, Fulani, Whona and lbo. The predominant occupation is rain fed agriculture and irrigation farming. They cultivate different varieties of crops such as maize, guinea corn, rice, beans, pepper, cocoa yam, cassava,. They also engage in some activities like hunting, rearing of animals, craft, weaving and blacksmithing [16]. The map of Borno state showing the study area is presented in Fig. 1.

\section{REVIEW OF RELATED LITERATURES}

Most developing nations, and certainly the majority of the populations living within them, depend directly on natural resources. Given the resource-dependence of rural populations in developing countries, and given that many natural environments and habitats are declining in these countries, it is tempting to conclude that poverty is a major cause of environmental degradation in poorer economies [18]. Nigeria blessed with rich and diverse flora, fauna and habitats that are declining in both quality and quantity due to unsustainable exploitation and misuse $[19,20]$. Most of the rapidly 
expanding population of the country are still rural and depends on the natural resources for their livelihood. Human assault on the environment continues to have far reaching consequences on the integrity of the planet and its living. The implementation of various International conventions and protocols, relevant to biodiversity conservation and environmental protection to which Nigeria is a signatory should be enhanced in order to achieve decent livelihood among rural dwellers [19].

Community involvement in protecting the environment of their impacted community and related environmental issues is generally supported for its potential to provide lowcost sources of information to government agencies, increased acceptance and confidence in government decisions, empowered community members on issues that affect them and advancement of democratic ideals. Reference [21], presented that for indigenous peoples and local communities, concern about the preservation and maintenance of traditional knowledge is not only motivated by the desire to conserve biodiversity as an end in itself, but also by the desire to live on their ancestral lands, to safeguard local food security and, to the extent possible, exercise local economic, cultural and political autonomy. Moreover, community involvement in protection and conservation of the environment by local residents can result in the collective transition of change [12].

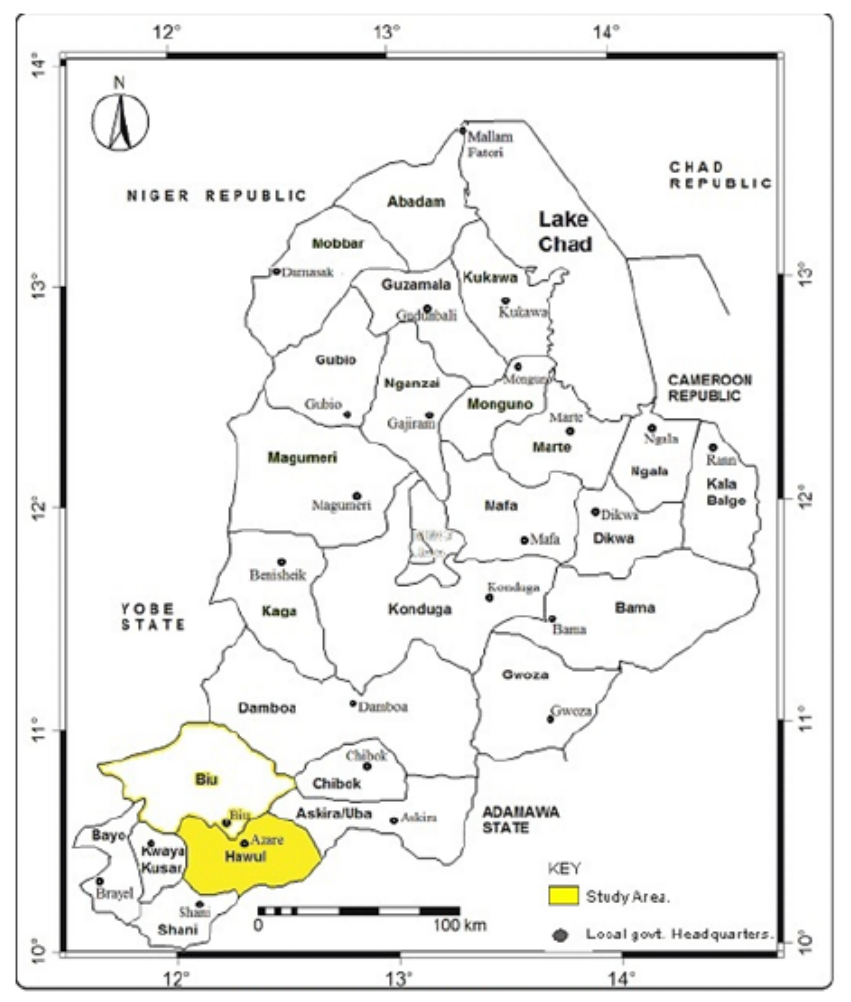

Fig. 1. Study area 
According to [10] the meaning of participation ranges from almost complete outside control, with involvement of local people, to a form of collective action in which local people set and implement their own agenda in the absence of outside initiators and facilitators. Several researchers argue, for example, that empowerment of stakeholders through participation can improve the environmental management process [22]. Participation is the involvement of a significant number of persons in situations or actions that enhance their wellbeing [23]. In [24] the authors found that the element of community participation to be consistently important. According to her participation in planning and implementation of programs can develop the self-reliance necessary among rural people for accelerated development.

In [25] reported conservation as the ethic of natural resource use, allocation and protection with the primary focus of maintaining the health of the natural world, which includes the forests, fisheries, habitats and biological diversity while, the secondary focus is on materials and energy conservation both very important to protect the ecosystem. According to him it is actually a social and political process which is necessary to take into account the local communities' needs. In developing countries, local communities are poor and their livelihoods depend a lot on natural ecosystems nearby (e.g. land, forests, and sea). Today, conservation is no longer restricted to protected area management. There is a global paradigm shift to include sustainable resource utilization and sustainable regional development in conservation. Past conservation failures have shown that weakness in engaging local communities and government contributes to poor conservation efforts. The study reported that elitist nature of conservation efforts often lack understanding of local dynamics and slow process of attuning projects and programs to local realities. As aptly pointed out the ongoing dialogue over protected area is becoming increasingly accepted; protected areas that involve indigenous residents are more successful [26].

Reference [27] presented Community participation (CP) as an active process by which beneficiary or client groups influence the direction and execution of a development project with a view to enhancing their wellbeing in terms of income, personal growth, selfreliance or other values they cherish. Community participation means some form of involvement of people, with similar needs and goals, in decisions affecting their lives. The advocates of community participation believe that it brings many lasting benefits to people instead of only a means of getting things done [28]. [29] said community participation is the creation of opportunities to enable all members of a community to actively contribute to and influence the development process and to share equitably in the fruits of development.

\section{METHODOLOGY}

The data collected for the study includes environmental problems in the area, levels of community participation, the role of government and the problems associated with community participation in environmental protection and conservation.

\subsection{Sampling Technique and Data Collection}

Purposive sampling techniques were used to select the study site. This is because the region is homogenous from physical, social/cultural religious and economic spheres. Quantitative data were obtained through administration of questionnaires. Respondents to the questionnaires were selected from Kida community. One hundred and fifty (150) questionnaires were administered in Kida Community. Simple random sampling technique was implemented to select households respondents. Data were analysed using descriptive statistical tools of frequency distribution. Percentages table and bar charts were used to summarize and describe the data. Qualitative data were generated through the use of in-depth interview and Focus Group Discussions (FGD). Interviews were conducted with eight (8) participants involving four men and women each. The snowball sampling technique was used as an identification tool for the in-depth interviews. The FGD consisted of two groups 
involving 12 youth; 6 men from Kida community. The participants are purposively selected based on their duration in the communities, willingness to participate, and referral and having ideas on the environment.

\subsection{Data Analysis Techniques}

Quantitative data were analysed using descriptive statistical tools of frequency distribution, Percentages table and bar charts were used to summarize and describe the data. Qualitative data were analysed through transcribing field notes and coding themes or categories and description used in the research report.

\section{RESULTS AND DISCUSSION}

This section discusses the results of the questionnaire survey administered to the respondents and the IDI and FGD. The information collected are on the environmental problems, who participates, ways they participate in environmental protection and conservation, benefits from environment, ways they affect the environment, problems faced in participation and government role in protecting and conserving the environment.

\subsection{Environmental Identified}

Some of the identified environmental problems include bush burning, felling of trees, erosion, windstorms and overgrazing. Table 1 presents the data on environmental problems in Kida community. Kida community as stated by respondents shows that the major environmental problems are bush burning with $(68 \%)$ and felling of trees with (24\%). The participants interviewed and the FGD stressed the most prevalent environmental problems identified in the study area were felling of trees and bush burning. A respondent in Kida said "Our environmental problem in Kida are felling of trees, bush-burning, loss of animal plant species but its the felling of trees that is affecting us because people need firewood to use and most of the women that cut the trees are not from Kida but neighbouring villages". Fig. 2 presents the environmental problems identified in Kida.

\subsection{Community Participation in Environmental Protection and Conservation}

The total percentage distribution of participants who participates in environmental protection is presented in Table 2 that in Kida (70\%) men; (2\%) women; (26\%) youths and (2\%) others. A graphical representation of respondents who participates in environmental preservation is presented in Fig. 3. The literacy rates of women and girls and their access to basic education which determine their level of environmental awareness are lower than men as presented by [30]. Participation statistics as shown in Table 3 in Kida $(62 \%)$ respondents indicated participation, (38\%) did not participate.

Table 1. Problems encountered in protecting the environment

\begin{tabular}{lcc}
\hline \multicolumn{1}{c}{ Problems Faced } & Frequency & $\%$ \\
\hline Felling of trees & 36 & 24 \\
Bush burning & 102 & 68 \\
Erosion & 0 & 0 \\
Loss of species & 6 & 4 \\
Windstorm, overgrazing & 0 & 0 \\
Uncertain & 6 & 4 \\
\hline Total & 150 & 100 \\
\hline
\end{tabular}


Table 2. Percentage of respondents who participate in environmental protection

\begin{tabular}{lcc}
\hline Participants & Frequency & $\%$ \\
\hline Men & 105 & 70 \\
Women & 3 & 2 \\
Youths & 39 & 26 \\
Others & 3 & 2 \\
\hline Total & 150 & 100 \\
\hline
\end{tabular}

Table 3. Respondents willing/ not willing to Participant in Environmental Protection and Conservation

\begin{tabular}{lcc}
\hline Response & Frequency & $\%$ \\
\hline Willing & 93 & 62 \\
Un-willing & 57 & 38 \\
Undecided & 0 & 0 \\
\hline Total & 150 & 100 \\
\hline
\end{tabular}

The attitudes of men are perceived to be good and encouraging in environmental protection and conservation as responded by FGD that "men play important role in protecting and conserving the environment more through planting of trees, some do terracing and enlighten people against cutting of trees while others do it for their personal use although, some are willing to participate but are discourage by the attitude of the Fulani herdsmen". In Kida community women reported that they only participate in environmental protection and conservation by terracing their farmlands in the mountainous or hilly sites.

\subsection{Methods of Participation}

Methods/ways of participation by Kida community as stated by respondents are presented in Table 4. In Kida $42 \%$ participate through planting of cover crops and making ridges along water run ways; patrol 44\%, awareness and educating people on the danger and effects on the environment $10 \%$, tree planting $4 \%$. [12] stated that community involvement in protection and conservation of the environment by local residents can result in the collective transition of change. A graphical representation of participation techniques employed by respondents is presented in Fig. 4.

\section{Table 4. Methods of participation}

\begin{tabular}{lcc}
\hline \multicolumn{1}{c}{ Participation Technique } & Frequency & $\%$ \\
\hline Community labour & 0 & 0 \\
Planting cover crops making ridges & 63 & 42 \\
Reporting defaulters to village head & 0 & 0 \\
Patrol & 66 & 44 \\
Educating people & 15 & 10 \\
Tree planting & 6 & 4 \\
Undecided & 0 & 0 \\
\hline Total & 150 & 100 \\
\hline
\end{tabular}

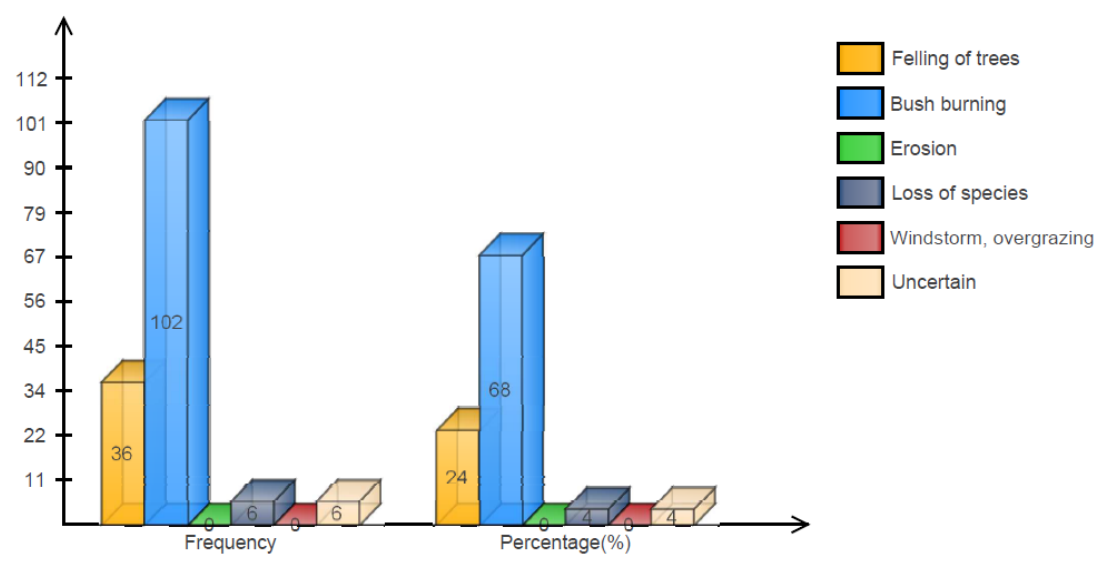

Fig. 2. Environmental problems 


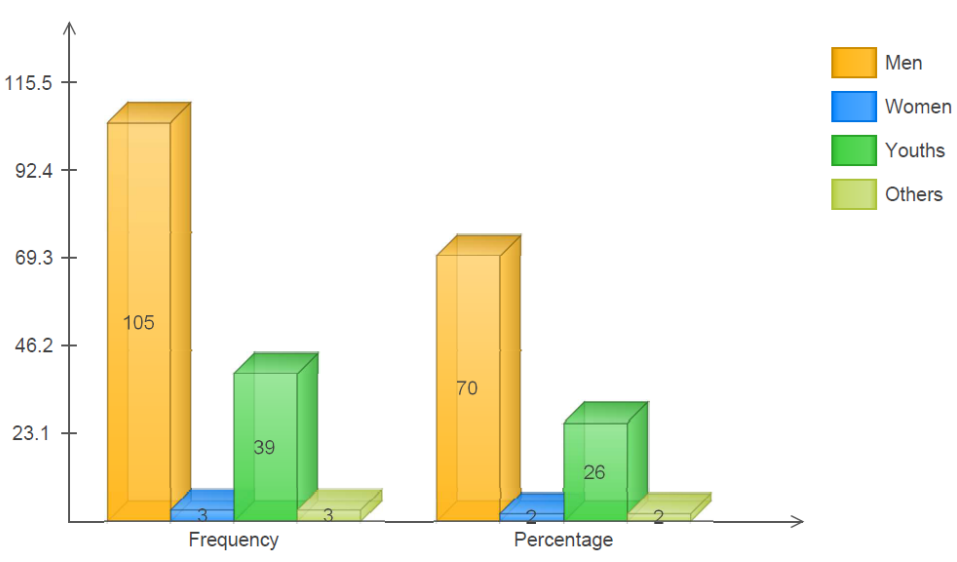

Fig. 3. Percentage of participants

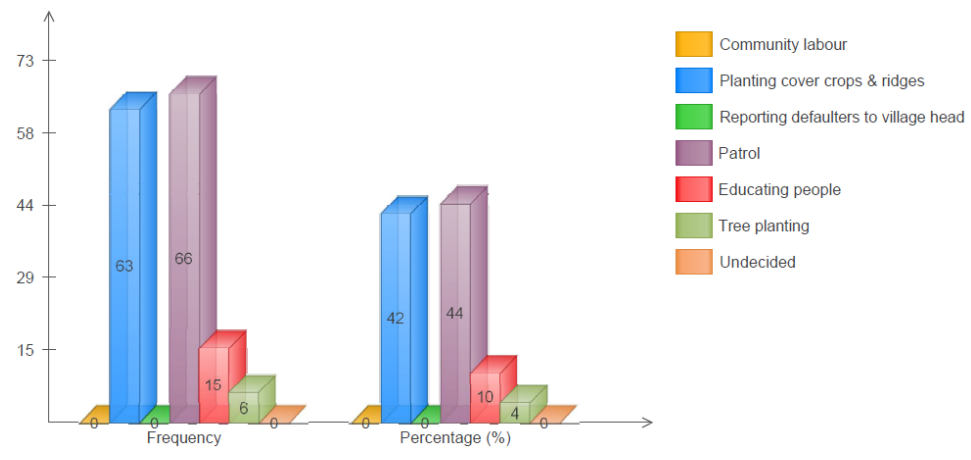

Fig. 4. Participation techniques

\subsection{Problems Encountered by Participants in Environmental Protection in the Communities}

The problems the community faced in protecting and conserving the environment as stated by respondents in Kida responses indicates 4\% do not face problems during participation; $94 \%$ indicated problems during participation as shown in Table 5. Some of the stated problems are represented in Table 6 . According to [31] farmers see bush burning as the best alternative of land preparation for cultivation. This is because they have the view that with burning, insect pests as well as weed growth that constitute a problem to crop yield is drastically reduced. The communities responded through IDI and FGD that they do encounter problems such as lack of seedlings, illegal cutting down of trees. The graphical representation of identified environmental problems in the community (Kida) is presented in Fig. 5 .

\subsection{Government Roles in Boosting Community Partici- pation in Environmental Protection and Conservation}

The various ways government (State) boost community participation to protect and conserve the environment as stated through responses is indicated in Table 7 where $88 \%$ of respondents in Kida indicates replanting of trees and patrolling of the forest area. National Policy on Environment encourages individual and 
community participation in environmental improvement efforts. Some of the Participants interviewed responded that government are involved in environmental protection and conservation through the provisioning of seeds for agriculture, seedlings of trees to be planted and in the FGD the community further stressed that government set of laws and forestry workers go to the forest for patrol to protect and conserve the environment.

Table 5. Does community faced problems?

\begin{tabular}{lcc}
\hline Response & Frequency & $\%$ \\
\hline Yes & 141 & 94 \\
No & 6 & 4 \\
Undecided & 3 & 2 \\
\hline Total & 150 & 100 \\
\hline
\end{tabular}

The need for environmental control arises from the fact that it brings improved health and better living conditions. Legal checks and balances are imposed on mankinds present activities, to prevent the upcoming generations from suffering for present generations reckless environmental damaging activities [32]. However, the major environmental problems in Nigeria which include deforestation, illegal hunting activities like bush burning and associated soil erosion, ozone layer depletion, desertification, acid deposition, global warming, oil pollution amongst others arise as a result of the ineffective enforcement of environmental laws [33, 34]. This ineffectiveness is ascribed to some challenges of enforcement which ranges from role conflicts in environmental management, corruption and bad governance prevalent in the country to inadequate enforcement facilities.

Table 6. Problems encountered in protecting the environment

\begin{tabular}{lcc}
\hline \multicolumn{1}{c}{ Problems Faced } & Frequency & $\%$ \\
\hline Selfish agenda & 3 & 2 \\
Hunters set fire & 3 & 2 \\
Lack of tree seedlings & 3 & 2 \\
Disobeying laws & 0 & 0 \\
Tree felling, overgrazing, bush burning & 123 & 82 \\
Lack of participation & 0 & 0 \\
Lack of environmental workers & 3 & 2 \\
Undecided & 15 & 10 \\
\hline Total & 150 & 100 \\
\hline
\end{tabular}

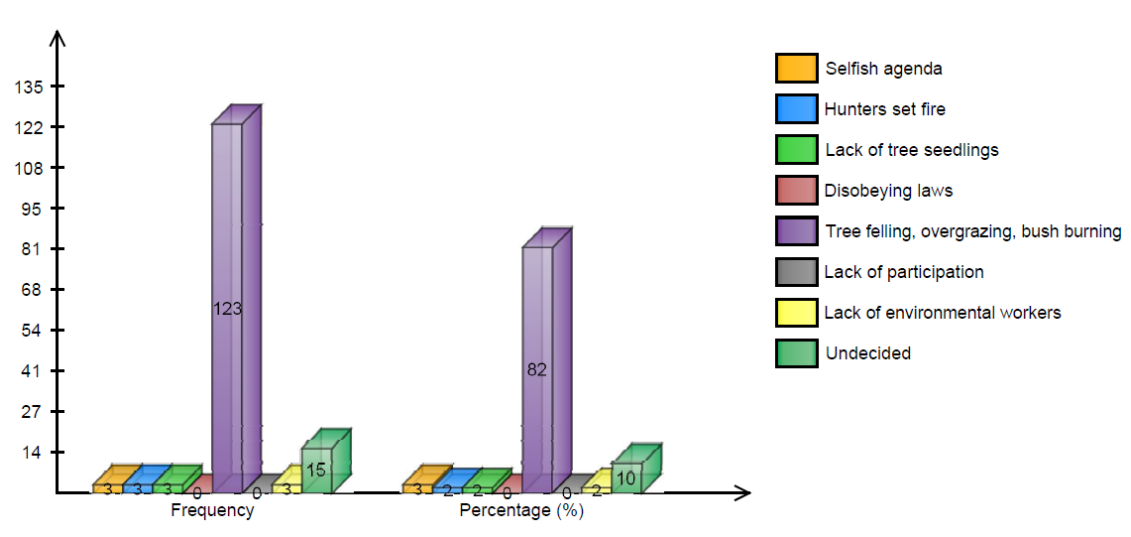

Fig. 5. Problems encountered 
Table 7. Government roles in boosting community participation in environmental protection and conservation

\begin{tabular}{lcc}
\hline \multicolumn{1}{c}{ Problems Faced } & Frequency & $\%$ \\
\hline Replanting of trees and patrol & 132 & 88 \\
Employing community workers & 15 & 10 \\
Controlling bush burning & 3 & 2 \\
Punishing defaulters/ fined & 0 & 0 \\
Enlightenment campaign & 0 & 0 \\
Fencing forest area & 0 & 0 \\
Providing seedlings & 0 & 0 \\
Undecided & 0 & 0 \\
\hline Total & 150 & 100 \\
\hline
\end{tabular}

\section{CONCLUSIONS RECOMMENDATIONS}

The primary objective of this research was to assess the environmental management system in Hawul LGA, Borno State of Nigeria, specifically of community involvement in protecting the environment. This is significant because Nigeria is a developing country, and that status influences how it addresses and manages its environmental issues. The objective of the research was attained through in-depth examination and analysis of literature on environmental issues in Nigeria, and discussions with local government officials from the Ministry of Environment and citizens of the community. The research findings established that major environmental problems faced include erosion, deforestation, bush burning, overgrazing and indiscriminate felling down of trees. It reveals that men do participate actively and attitude is good toward participation. However, they faced problems in participating in environmental protection and conservation such as setting bush on fire, lack of tree seedlings, disobeying laws, lack of environmental workers to educate farmers, deforestation and overgrazing. The finding further reveal government important role in boosting community participation through replanting of trees, patrolling and employment of community workers.

We would recommend far more emphasis on enforcement of laws on illegal activities on natural environment as presented in [35]. Developing viable local institutions and generating public understanding and support for both economic development and environmental conservation constitute a formidable challenge. Resource managers and environmental scientists must assume positions of status and responsibility equal to those of development-oriented professionals.

Based on the results the following recommendations are made for active community participation in environmental protection and conservation in Hawul LGA of Borno State.

(i) Policies and laws of Environment protection should be enforced to help in protecting and conserving the environment;

(ii) Alternative to firewood and charcoal should be provided to reduce cutting down of trees;

(iii) Public enlightenment should be given consideration to the community on the danger of not protecting and conserving the environment;

(iv) Department of natural resources and agriculture in Hawul LGA should involve community to participation in environmental protection and conservation; this will increase dissemination of information and more awareness to the rural populace; 
(v) Extension officers to be employed and posted to the districts in order to orient and educate populace to know the danger and hazards associated with illegal utilization of community natural resources;

(vi) The local community citizens should be actively involved in the processes of Environmental Protection;

(vii) Government should actively participate through proper enlightenment campaign;

(viii) Government should enact laws to punish defaulters either through punishment or fines.

\section{ACKNOWLEDGEMENT}

The authors wish to acknowledge the citizens (respondents) of Kida local government area for their cooperation and support. Also, we wish to acknowledge the environmental staffs of the local government for their compliance and support to the success of this research.

\section{COMPETING INTERESTS}

Authors have declared that no competing interests exist.

\section{References}

[1] Megaze A, Balakrishnan M, Belay G. The attitudes and practices of local people towards wildlife in Chebera Churchura national park, Ethiopia. International Journal of Biodiversity and Conservation. 2017;9(2):45-55.

[2] Newmark WD, Leonard NL, Sariko HI, Gamassa DGM. Conservation attitudes of local people living adjacent to five protected areas in Tanzania. Biological Conservation. 1993;63(2):177-183.

[3] Yusuf HO, Lawal Al. Womens participation in natural resource conservations in Giwa
Local Government area of Kaduna State, Nigeria; 2005.

[4] Adeyemo AO. Assessing environmental protection and management systems in West Africa: A case study of Nigeria. Southern Illinois University at Carbondale; 2008.

[5] World Bank. Agriculture Investment Sourcebook Agriculture and Rural Development. Washington, DC: World Bank. World Bank; 2005.

Available: https://openknowledge.worldbank .org/handle/10986/7308 License: CC BY 3.0 IGO

[6] YueP. The environment needs public participation; 2005.

Available: https://www.chinadialogue.net /article/show/single/en/604-The-environment -needs-public-participation

[7] Soriano-Redondo A, Bearhop S, Lock L, Votier SC, Hilton GM. Internetbased monitoring of public perception of conservation. Biological Conservation. 2017;206:304-309.

Available: http://doi.org/10.1016/j.biocon. 2016.11.031

[8] Okaka W. Developing regional communications campaigns strategy for environment and natural resources management policy awareness for the East African community. Res J Environ Earth Sci. 2010;2(2):106-111.

[9] Bockstael E, Bahia NC, Seixas CS, Berkes F. Participation in protected area management planning in coastal Brazil. Environmental Science \& Policy. 2016;60:110.

[10] Kambani C. Forest resource utilization, local participation and management: a study of Namizimu Forest Reserve in Lungwena, Southern Malawi; 2005.

[11] Bragagnolo C, Malhado AC, Jepson P, Ladle RJ. Modelling Local Attitudes to Protected Areas in Developing Countries. Conservation and Society. 2016;14(3):163.

[12] Prizzia R. Community involvement in protecting the environment: The role of Restoration Advisory Boards (RABs). The Innovation Journal: The Public Sector Innovation Journal. 2005;10(1):1-16. 
[13] Buckingham-Hatfield S. Gender and environment. Routledge; 2005.

[14] Larson EL. United Nations Fourth World Conference on Women: Action for Equality, Development, and Peace (Beijing, China: September 1995). Emory Int'l L. Rev. 1996;10:695.

[15] Huynen MM, Martens P, Hilderink HB. The health impacts of glottalization: $A$ conceptual framework. Globalization and health. 2005;1(1):14.

[16] Yakubu D. An analysis of the determinants of land use dynamics in Hawul L.G.A, Borno State. An thesis in the department of Geography, university of Maiduguri. Borno state; 2009. (unpublished).

[17] National Population Commission. Maiduguri, Borno State; 2006.

[18] Barbier EB. Poverty, development, and environment. Environment and Development Economics. 2010;15(6):635660.

[19] Adisa BO, Adeokun OA, Oladoja MA. Nigerian's threatened environment: An obstacle to rural poverty eradication. Journal of Environmental Extension. 2005;5(1):51-59.

[20] Chowdhury MSH, Gudmundsson C, Izumiyama S, Koike M, Nazia N, Rana MP, Mukul SA, Muhammed N, Redowan M. Community attitudes toward forest conservation programs through collaborative protected area management in Bangladesh. Environment, development and sustainability. 2014;16(6):1235-1252.

[21] Langton $M$, Palmer L, Rhea ZM. Community-oriented protected areas for indigenous peoples and local communities. Indigenous peoples, national parks, and protected areas: A new paradigm linking conservation, culture, and rights. 2014;84.

[22] Armah FA. Local Participation in Water Resource Management: Case study of old Fadama Community, Ghana (Doctoral dissertation, Lund University); 2008.

[23] Cohen JM, Uphoff NT. Participation's place in rural development: Seeking clarity through specificity. World Development. 1980;8(3):213-235.
[24] Lele U. The design of rural development. Lessons from Africa. Johns Hopkins University Press; 1975.

[25] Zabbey N. September. How to ensure peaceful and sustainable natural resources exploitation and ecosystem protection: The Case of Ogoni and Andoni. In Paper Delivered at the Workshop Empowerment of Women and Youths in the Niger Delta for Conflict Organized by Niger Delta Environment and Relief Foundation (NIDEREF). 2009;30.

[26] Abdulhalim S, Hood S, Ibrahim K, Mazlin M. Enhancing Local participation In Resource Management and Conservation through learning: Experience from Langkawi Island, Malaysia. Institute for Environment and Development, University Kebangsaan, Malaysia; 2008.

[27] Yindego G. Community Participation and Sustainable Soil and Water Conservation Management case study of zala-daget project:Dogua Tembien Woreda- Tigray Highlands (Doctoral dissertation, aau); 2004.

[28] Hamdi N, Goethert R. Action planning for cities: a guide to community practice. Chichester: John Wiley. 1997;264.

[29] Mazinyo SP. Community participation in solid waste management in high-density low-income areas: the case of C-Section in Duncan Village (Doctoral dissertation, University of Fort Hare; 2009.

[30] Tata MY. Effects of community forest protection on women in Michika LGA, Adamawa State, Nigeria. Unpublished raw data submitted to Department of Geography, University of Maiduguri; 2015.

[31] Takon TJ, Amalu TE, Okpara DE. Assessment of local people's attitude towards natural resource conservation in Boki local government area of Cross River state, Nigeria. Research Journal in Organizational Psychology and Educational Studies (RJOPES). 2013;2(1):60.

[32] ljaiya $H$, Joseph OT. Rethinking environmental law enforcement in Nigeria. Beijing L. Rev. 2014;5:306. 
[33] Egbon PC, Behrooz M. Environmental policy planning. National Centre for Economic Management and Administration; 1996.

[34] Aluta E. Participatory water governance in Nigeria: Towards the development of an effective legal framework for rural communities (Doctoral dissertation, University of the West of England); 2017.

[35] Murtala MG. An appraisal of the laws on protection of environment in Nigeria. ExpressO; 2015.

(C) 2017 Bassi et al.; This is an Open Access article distributed under the terms of the Creative Commons Attribution License (http://creativecommons.org/licenses/by/4.0), which permits unrestricted use, distribution, and reproduction in any medium, provided the original work is properly cited.

Peer-review history:

The peer review history for this paper can be accessed here:

http://sciencedomain.org/review-history/19139 